\title{
Social Learning Analytics in Higher Education. An experience at the Primary Education stage
}

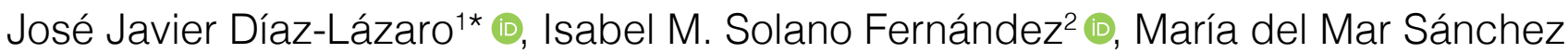 \\ Vera $^{3}$ (D) \\ 'Vice-Rectorate for Virtual Learning, Universidad Católica de Murcia, Spain \{jdiaz@ucam.edu\} \\ 2Department of Didactics and School Organization, University of Murcia, Spain \{imsolano@um.es\} \\ 3Department of Didactics and School Organization, University of Murcia, Spain \{mmarsanchez@um.es\} \\ Received on 28 January 2017; revised on 27 February 2017; accepted on 20 March 2017; published on 15 July 2017
}

DOI: 10.7821/naer.2017.7.232

(c)) BY-NC-ND

\begin{abstract}
The concept of Learning Analytics, as we understand it today, is relatively new but the practice of evaluating user behavior is not innovative. For years, technological development, along with other educational aspects, have encouraged, developed and facilitated this practice as a way of providing a personalized quality experience to students. The main goal of this study, carried out in the Primary Education Degree of the University of Murcia, was to research, from the perspective of Social Learning Analytics, how students learn and collaborate in online environments, specifically through their use of social media. With the idea of improving and optimizing future teaching experiences, a pilot study was conducted using weblog, Twitter and Facebook to work with different topics on the subject. The method used in this research was a participant observation and the analysis performed was both quantitative, based mainly on the data gathered from the learning analytics, and qualitative (analyzing students' content from comments). Results show that there was greater interaction on Facebook than weblogs, where students interacted to deal with aspects related to the learning process and the topic of the subject. This exchange of information grew during the development of the experience. In addition, learning analytics shows that there is a relationship between group members and their interaction and behavior in networks.
\end{abstract}

KEYWORDS: EDUCATION, INFORMATION TECHNOLOGY, CLASSROOM TECHNIQUES, SOCIAL LEARNING, SOCIAL INTERACTION

\section{INTRODUCTION}

The evolution of the Internet has afforded new ways of formal and informal communication and has favored the use of new channels of collaboration among users. These tools in turn accumulate more data (the number of times we watch a video, the number of times we consult a resource, those with whom we interact online). All the above provide huge amounts of information, and this growing quantity of information has come to be known as Big Data.

The world of Big Data is not exclusive to education, but it is being applied more and more in this field, so it becomes feasible

*To whom correspondence should be addressed:

Vice-Rectorate for Vitrtual Learning, Universidad Católica de Murcia Campus of Los Jerónimos, Guadalupe 30107

Murcia (Spain) to talk about Learning Analytics. According to the first conference on Learning Analytics and Knowledge held in 2011, this is the measuring and collecting of data in order to analyze and improve the educational context. As Siemens and Long (2011) state, the future of education emphasizes new technologies, mobile devices and flexible designs in the classroom, but the key factor in the future of Higher Education is something that we can neither touch nor see, since basing decision making on huge amounts of data and tests can improve performance and organizational productivity and also students' learning. We can, therefore, define Learning Analytics as the application of the massive use of data to improve learning (Clow, 2013). Incorporating these tools and communicative strategies into the sphere of education means that it is of interest to analyze how students learn and collaborate when using these tools and applications. This is of great value when, for example, adapting teaching plans to particular needs and to the learning process. From a more enriched standpoint, LA (Learning Analytics) can be defined as an emerging research field, which seeks to make use of data analysis to inform and take decisions at all levels of the education system (Johnson et al., 2013)

The development of Learning Analytics can be understood from various perspectives:

- Educational Data Mining (Clow, 2013). This seeks to develop methods to analyze educational data and focuses on technical aspects rather than pedagogical ones. The programs or applications used enable:

- Learning Analytics in data visualization. Within this typology would lie many of the tools that we can find today that offer the possibility of visualizing data from students' work. Some of these are integrated within institutional VLE environments. This is what Clow (2012) calls metrics when referring to how data is visualized.

- Learning Analytics in adaptive learning. Here we are not noting only a descriptive reading of Big Data, but also of the possibility of predicting and of recommending how students can improve their own learning process.

- Academic Analytics (Clow, 2013). This model includes more pedagogical perspectives and is characterized by its focus on Higher Education contexts. It should be borne in mind that although LA has been particularly fruitful in online courses or open Higher Education, in the conventional classroom setting it is crucial to include the information that 
comes from the variety of activities carried out therein in order to capture fully the wealth of learning experiences that are being realised (Monroy, Snodgrass, \& Whitaker, 2014).

- Social Learning Analytics (SLA). This is the learning environment itself that the student has to work with online and contacts that are analyzed (Personal Learning Network or PLN). These include virtual spaces or environments of a formal or informal type, the various social media and resources, telematic tools and others, all of which comprise a student's Personal Learning Environment (PLE). According to Ferguson and Buckingham (2012), the SLA focuses on the development of relations and offers the possibility of identifying interventions that can enhance the potential of the network to support the learning of the actors.

While most studies, e.g., Douglas, Bermel, Monzurul Alam and Madhavan (2016), seek to identify learners (what they are like, what they use, how they relate with each other), it is the use made of this data and our concept of it that will lead us to adopt one position or another.

We therefore state that Learning Analytics can be understood as a series of tools that help us to use data about students to improve teaching and learning processes in virtual contexts, and this is the standpoint that we adopt in this paper. According to Clow (2012), one of the problems of applying some models of Learning Analytics lies in the consideration that the assessment is the final result, when understanding it as part of the educational process enables us to enrich the learning experience.

We are, of course, aware that counting the number of clicks that a student makes does not imply that we can analyze that student's learning (learning is a far more complex process than that), but for the same reason neither can we forego studying LA from an educational perspective. One of the aims of LA is to provide students with better information about their progress and what they need to do to fulfill their educational goals. This has huge potential to transform their own learning and provide a continuous, personalized educational response as they advance (Sclater, Peasgood, \& Mullan, 2016).

For Ferguson and Buckingham (2012), online social learning is becoming an important phenomenon, a transcendental challenge; it is paving the way towards an even greater challenge, the application of a pedagogical type analysis in a context where power and control of information are of are of paramount importance. The analysis of social learning can offer new ways to advance. Thus, the analysis of students' learning is understood as being more individualized, while considering the broader context in which they learn along with others in a collaborative space that is being fostered by social networks and Web 2.0 tools and applications.

\subsection{Social Learning Analytics in Higher Education}

The development of more active methodologies among students at our universities and the incorporation of the emerging technologies have created spaces for collaboration that foster and encourage the active role of students in a climate which favors communication, relations and working together and with teachers and professionals with Web 2.0. tools and applications. So, knowing how these interactions work will give us a lot of information to adapt our teaching to how our students learn. The procedure followed here seeks to enhance the effectiveness of student participation in real time, with specific tools being used to analyze their interactions in online spaces for the debate and realization of tasks as part of their learning process. As Sclater, Peasgood \& Mullan
(2016) state, the social analysis of students on social networks focuses on the type of interactions produced and the quality of these. In a similar vein, De Laat and Prinsen (2014) comment that SLA is necessary in educational frameworks in social interaction environments, since it is important to understand the social mobility in a student's learning.

Starting from some research into Higher Education (Dahlstrom, Walker, \& Dziuban, 2013), the advantages of using Web 2.0 tools and applications in learning are highly rated by students. When, moreover, collaboration spaces are generated, these have a decisive role in their learning, with group members and colleagues considered to be the most influential agents in their learning. This is where the student learns, mainly from peers, and this generates an atmosphere of active, autonomous and collaborative learning. If we analyze how students learn at the social level with other agents, their strategies and their way of acting, which tools they use and how, then we will be able to adapt teaching plans to their needs and to their own style of social learning.

Starting from the theoretical contributions, in particular the study by Drachsler (2011), which explain how LA, and in particular SLA work, various dimensions can be identified. Among the agents interested in the analysis of social learning are the educational institutions themselves and potential service providers. Within the educational context itself, the main parties interested are the teachers and students (Johnson et al., 2013), with many of the decisions taken by the teachers having an important effect on the future success of their students" (Oblinger, 2012). Whoever the main agents are, their final goal will always be to advance educationally (Ferguson and Buckingham, 2012). The main aims in the SLA are reflection and prediction, since on the basis of this analysis there is a search for methodological/pedagogical advancement in student learning, that will enable them to achieve success in their education. Studies like that by Leon et al (2015) conclude that correct use of the SLA in the classroom can help to better understand student interactions and also their behaviors and performance.

\section{METHOD}

\subsection{Aims}

This pilot study forms part of a wider piece of research that seeks to appraise the social learning of students of Higher Education by setting up networks or virtual spaces and the use of web 2.0. applications and tools, and so analyse their learning. The general and specific aims of this part of the research are:

(1) To analyze the trends of Learning Analytics and the use of Big Data in educational environments.

(2) To ascertain and describe the various tools and applications that students can use to interact and collaborate with other students in their learning with others.

(3) To describe the habits, interactions and specific tools used in students' educational process and so manage their social learning.

(4) To evaluate and analyze students' interactions through the various tools and applications they use.

(5) To carry out a joint evaluation of students' social learning after compiling and analyzing the information collected during the experiment together with the possibilities that Social Learning Analytics affords. 
Listing these aims here provides an overall view of the research undertaken. In any case, for reasons of space, in this paper we present only a part of the information collected, which refers, as already mentioned, to the pilot study and, specifically, to the data obtained form the evaluation and analysis of the students' interactions through various tools and applications (Aim 4).

\subsection{Process and method}

The research methodology is mainly of a quantitative nature since the focus is on Learning Analytics. Nevertheless, it should be noted that the information collected is both quantitative and qualitative and, hence, both quantitative and qualitative techniques are used for its analysis. We can, therefore, note a mixed approach in the sense defined by Hernández, Fernández and Baptista (2010). Rather than going into the qualitative-quantitative debate, and especially when talking about learning analytics, we adopt the posture held by Romero (2001), Henríquez (2001) and Henríquez (2003), which sees qualitative and quantitative elements as being complementary in research in education.

The research was carried out through an educational experience, and in the case in question here the researcher in charge of evaluating the experience and the teacher were one and the same. The researcher is therefore also a moderator and participant, who when collecting the information is also part of a direct observation process. The fact that the researcher both performs and evaluates the educational experiment enhances the knowledge of the reality of what is being realised. Lastly, inside awareness of the context of the experiment, knowing the participants and interacting with them offers a more global view of the situation, its characteristics, the characteristics of the participants and an understanding of the how and what of each situation evaluated and analyzed in the ongoing research. On the other hand, we also need to consider that this type of study has some limitations, such as the scarce control of strange variables, a possible dependence on subjective judgments and reactivity issues that derive from being observed (Ato, López, \& Benavente, 2013)

\subsection{Participants}

This experiment was undertaken as part of the subject Research and ICTs, given to Group 4 of the First Year of the Degree Course in Primary Education at the University of Murcia (year 2015/2016). The group comprised 68 students. The aim of the experiment was to improve and optimize the future experience programmed for February to June 2017, so we are dealing here with a pilot study to construct tools and analyze and put them into practice. The educational experience of the students comprised six group tasks performed in collaboration which were presented, published and disseminated via blogs set up by the students themselves, and which were advertised, presented and discussed in a private classroom group set up on Facebook specifically for the purposes of this research, and called Investigación y TIC. Grupo 4. The idea was to foster student interaction and social learning. For interaction outside the classroom we used Twitter so that we could share the experience with other users of this environment using a label or the hashtag for the subject. The 6 groups carried out their practical and collaborative work both inside and outside the classroom.

\subsection{Instruments and procedure}

Methodologically, this research used various instruments, techniques and tools to collect data for quantitative and qualitative analyses and thus provide a more holistic understanding of the issue under research. Information was collected using observation techniques and observation grids were then used to complement the quantitative data obtained. Likewise, tools were selected for the learning analytics that enable monitoring while at the same time providing the necessary information about the interaction and communication being conducted among the students, the creation and publication of contents, thus offering an analysis of the social learning produced among the students during their educational process. The quantitative nature of the data provided by these tools will help us to understand the extent to which the statistic of the number of interactions and how students learn with others by using a variety of tools really affects their learning.

Information on student interaction in these virtual spaces was collected on the platforms themselves for later analysis. Various instruments were built to collect the necessary information for this pilot study: an initial questionnaire on social learning and ICTs in education, an observation grid on the social learning carried out in the classroom during the performance of tasks, and a final evaluation and satisfaction questionnaire on social learning and ICTs in education. All the tools underwent due validation processes by expert judges. The Netvizz tool was used to extract online activity and social learning.

The working plan of the research in which this pilot study is situated comprises 5 Stages, which each seek to meet the aims established. This pilot study will give some answers regarding the appropriateness of the instruments and programs used for the social analysis of the students and also about any aspect that needs to be modified in part or completely and so improve and optimize the research as a whole.

The 5 Stages are cyclical, since once executed they return to the starting point in order to enhance and optimize the final research experience. The stages are outlined below.

- Stage 1. Systematic review of the tendencies of Learning Analytics and the use of Big Data in educational environments.

- Stage 2. Creation and selection of tools and instruments for data collection.

- Stage 3. Data collection.

- Stage 4. Analysis of the data collected using statistics packages and network analysis tools, and also by reduction of content and categorization according to origin and type.

- Stage 5. A joint assessment of students' social learning and the possibilities provided by Social Learning Analytics.

\subsection{Data treatment and analysis}

Given the diverse nature of the information collected, different procedures and tools were used to extract and analyze it, depending on whether the information was quantitative (mainly, learning analytics) or qualitative (observation of the student interaction and collaboration). For the quantitative data we used basic descriptive statistics (frequencies and percentages) run on SPSS as well as the Gephi application, which enables the generation of graphs of the interactions over the social networks. For the qualitative data, we used the program Nvivo to analyze the contents. In this sense, the information on the daily activity on Facebook and the type of post placed by the students was extracted using Netvizz, and analyzed with the basic descriptive statistics. The information on the interaction (posts by members, reactions by members and comments by members) was extracted with Netvizz and analyzed through Gephi. This first part of the quantitative data analysis was completed and tested with qualitative analysis techniques in 
Nvivo - specifically, the information obtained through the type of post, according to content and comments made by the students about their colleagues' posts.

\section{RESULTS}

This paper focuses on the results of students' activity and interaction with others in their collaborative learning via a network, in this case a Facebook group created for the subject in question. Thus, in terms of the general daily activity in the Facebook group, we analysed the number of interactions via posts, reactions, likes, comments, and numbers of shares. As Graphic 1 shows, the number of posts uploaded during the experiment is much lower, together with comments and shares, than the reactions, in general, and the "likes" in particular. While the peaks for all the interactions are related to the group tasks, it is notable that "likes" are the main interaction while comments on posts are scarce, generally no more than 5 per post, although one post generated over 30 comments.

Focusing now on the nodes (the members of the group), and not on the edges (interactions), and bestowing an attributed value to them -in this case the posts published by the members, where the size of the node and its colour increase or are intensified as number becomes larger-it can be observed in Graphic 2 how the moderator with the largest number of published posts (22), is followed by 6 students, who interact with a higher number of posts $(>5)$ than their colleagues. These students are; Student 2, Student 28, Student 12, Student 6, Student 45 and Student 55. Another noteworthy finding was that more than 20 students of much lower interaction activity $(<1)$, showed little initiative in publishing posts.

Again in reference to this attributed value referring to the posts made, Graphic 3 shows that 72 of all the posts correspond to or attach additional information through a link to an external site. This is frequently because many of the tasks are carried out in a group blog. 21 posts contained additional images; 17 included videos or links to videos; lastly, 7 were posts that only included text.

According to the type of posts, a qualitative analysis which codes them and classifies them as nodes (see Graphic 4) shows that over half have are concerned with students' sharing the tasks done in groups as part of their training. To a lesser extent, the posts deal with questions by the moderator aimed at fostering group discussion and with class group presentations.

A qualitative analysis of the students' comments on posts leads to these being classified into four large topics: the teaching and learning process, the possibilities afforded by ICTs, digital competencies and positive ratings of tasks. As Graphic 5 shows, in treemap form that the topic most commented on is the teaching and learning process. Within this, the most commented on sub-topics are those relating to personal learning adapted to the student and the personalized teaching according to the methodology used by the teacher. Another topic in which there were a lot of comments on students' posts was the possibilities that ICTs can provide. In this category, the sub-topics that stand out are those that relate to the spatial and temporal possibilities ICTs afford, their impact in the classroom and the creation of shared knowledge. One issue that was treated to a lesser extent was the need for digital competency, on the part of teachers and students alike. Finally, the issue referred to least was concerned with students' positive ratings of the group published tasks.

If we focus on the reactions of the students (likes, loves, etc.), where the size of the node increases and the color is more intense when the number of reactions is higher, we see, as is shown in Graphic 6, that 3 students stand out from the rest (Student 1, Student 2 and Student 3), whose reactions are far higher than the others' $(>70)$. They are followed by 15 students $(>30)$. While the other members show some activity, this is considerably lower, with 7 members, Student 58, Student 59, Student 60, Student 61, Student 62, Student 63 and Student 64 reacting much less than the others $(<2)$.

When giving an attributed value to students' comments, where again the size of the node is bigger or the colour is more intense as the number increases, we observe from Graphic 7 that 4 members stand out from their colleagues in terms of their interaction through comments on posts ( $>3$ ): Student 8 , Student 3, Student 2 and Student 12 . They are followed by 7 members in this respect, while there are 27 students who participated less in this type of interaction $(<1)$.

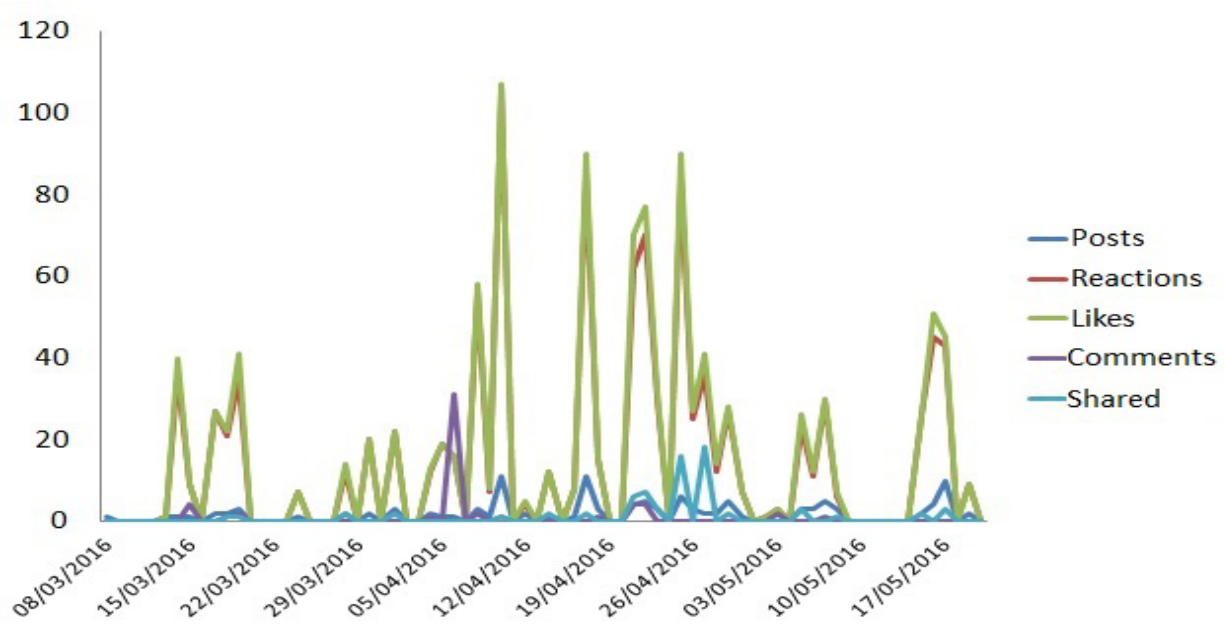

Figure 1. Daily activity on Facebook 


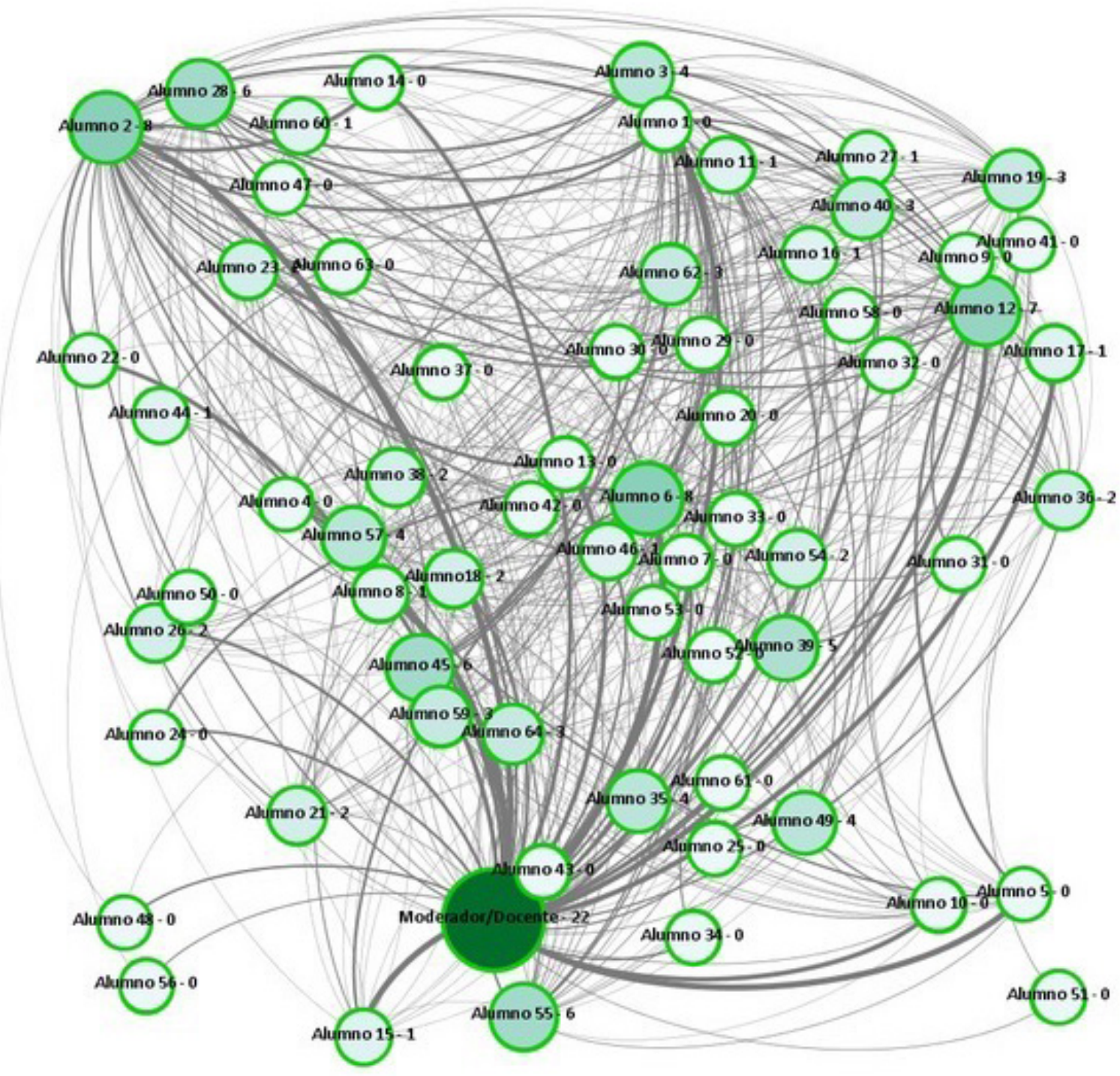

Figure 2. Interaction. Posts per member

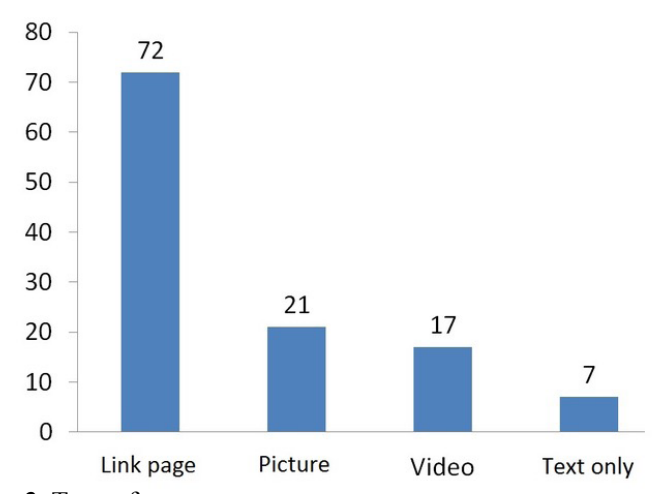

Figure 3. Type of post

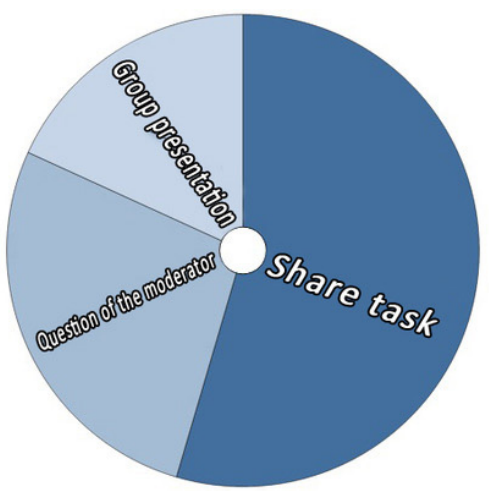

Figure 4. Type of post according to content 

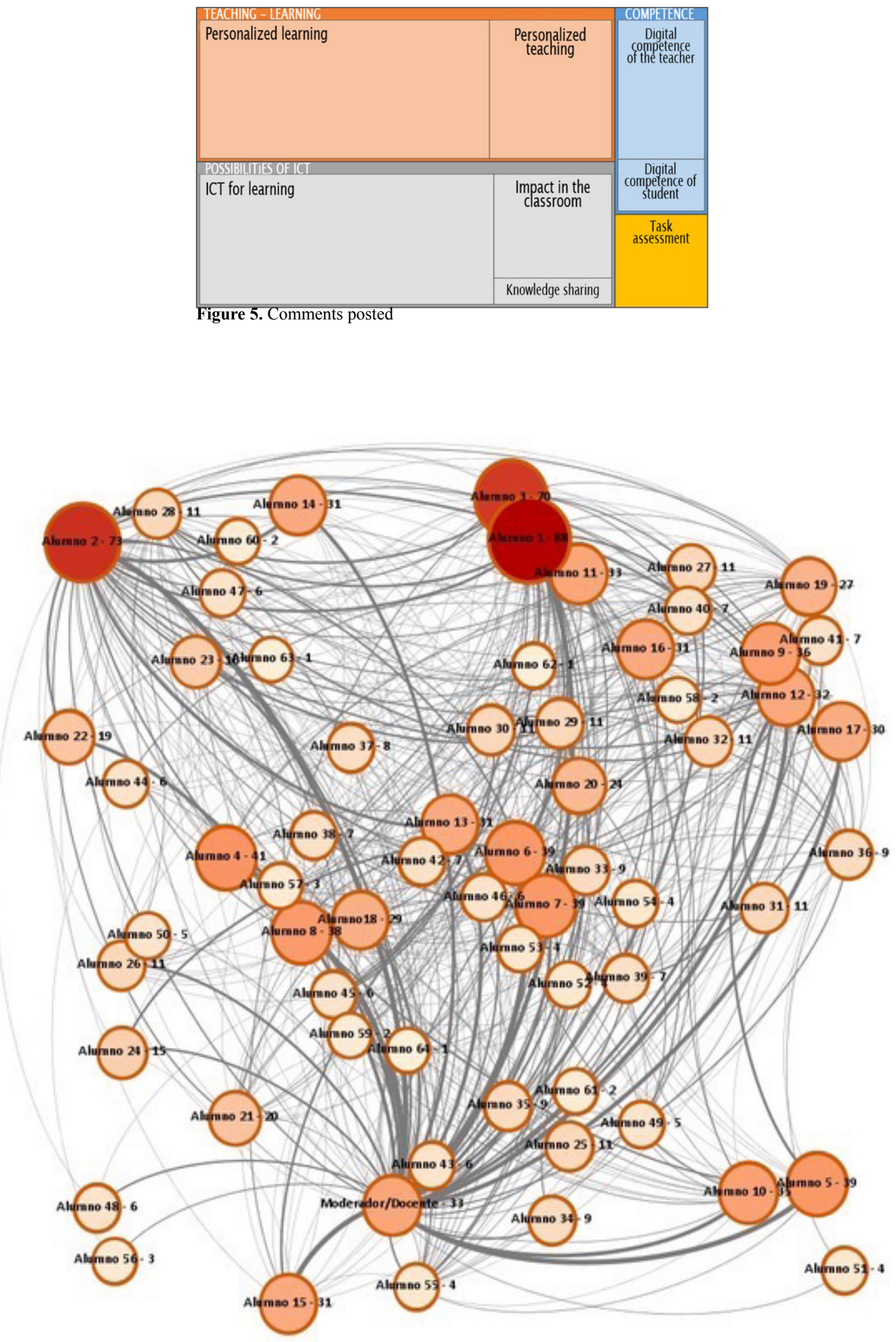

Figure 6. Interaction. Reactions by member 


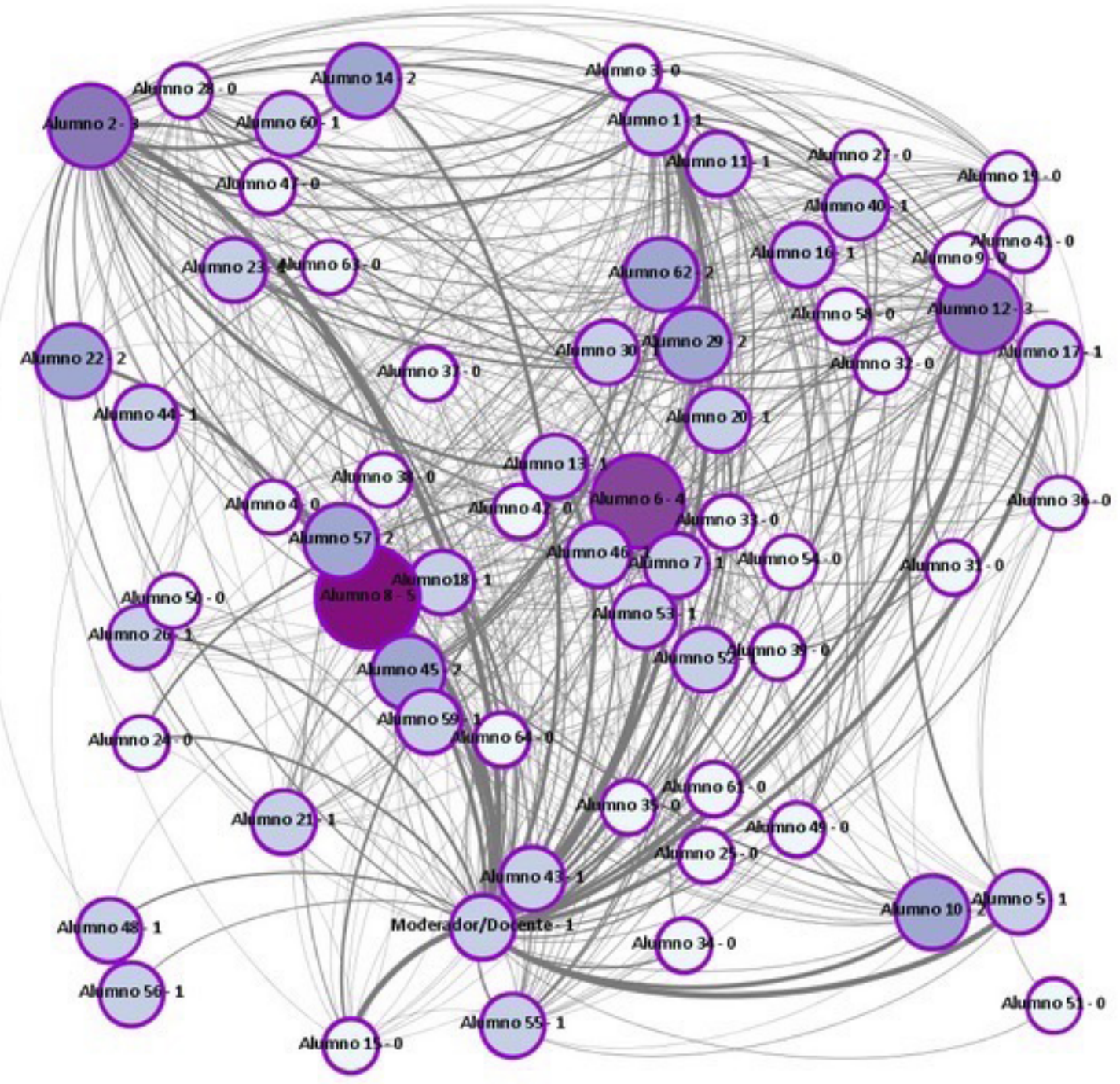

Figure 7. Interaction. Comments by member

\section{DISCUSSION AND CONCLUSIONS}

From the results it is concluded that the purpose of this pilot study has been fulfilled, as have the stated aims of the research of which it is a part.

The relations in terms of the interactions of the Facebook group develop from a direct interaction between the moderator (teacher) and the students, and this leads to the participation of the rest of the students, and the interaction grows. The interactions increased as the experiment progressed both in the number of interactions and of the members involved in them. Likewise, the type of interactions were direct and fast, as is characteristic to a social network, with "like" being more frequent than other more laborious or longer contributions like posts or comments on posts.

This data reflects, as Leon, Corona, Yedra, Cruces and Gómez (2015) indicated, that the correct use of the SLA in the classroom can help to ascertain better the interactions of students, their behaviors and their performance.

Learning analytics show a relation for the members of the group and their interactions and behaviors, with at least $10 \%$ of students standing out in terms of total interactions, reactions and comments, posts published and the reactions to these. More than half of these students coincide in all cases and types of interac- tions above as being the most active. Within this type of pyramid, we find that at least $23 \%$ of the students would be in the top half in the number of interactions, with the remaining $67 \%$ at the base. Within this base of the pyramid made up of the less active students, 2 students stood out for their little or practically non-existent activity, below all the others. With the data from this study we cannot confirm that the most active students are those with the best academic performance, but we have considered this as a hypothesis for the research work to be carried out the coming academic year.

While more than half of the students' posts had to do with task sharing, the comments on the posts dealt with sharing and debating the teaching and learning process and the educational possibilities ICTs offer.

The digital competence of the teacher and the students occupies a small space in the comments and debates of the Facebook group.

Of interest is the students' autonomy when debating and reflecting on the possibilities ICTs afford for education. According to Hernández, González, Jiménez and Chaparro (2016), online social learning analytics are a relatively new field so we are only just becoming aware of their possibilities and applications in education. By seeking to analyze what students are doing we may find 
information about spontaneous interactions, which will provide valuable information about the teaching-learning process.

The pilot study presented here serves as a base, therefore, to design a new teaching experience grounded in the use of learning analytics, collaborative work by students and interaction via social networks. Specifically, the data obtained were used to take a series of concrete decisions to be put into teaching practice. These included the elimination of blogs as a portfolio, since it was understood that the social networks were sufficient spaces in themselves to provide evidence of students' learning, the fostering of student interaction on the basis of the above evidence and reflecting on the learning process. Thus, a rubric was prepared from each of the learning activities which, as well as evaluating aspects of content, collects criteria about collaborative learning drawn from the pilot study and which constitute a fundamental aspect of the assessment of students' learning. This pilot study has favored a teaching coordination process among the teachers participating, which has unified the criteria and subject tasks given in different groups.

As stated by Nunn, Avella, Kanai and Kebritchi (2016), the need is highlighted for a better understanding of what is being realised in the networks in order to study the data and optimize the results obtained. These can then be used to enhance teaching and learning. These types of studies can, therefore, be useful in promoting educational approaches that enhance students' learning.

\section{REFERENCES}

Ato, M., López, J. J., \& Benavente, A. (2013). Un sistema de clasificación de los diseños de investigación en psicología. Anales de psicología, 29 (3), 1038-1059. doi:10.6018/analesps.29.3.178511

Clow, D. (2012). The learning analytics cycle: closing the loop effectively. In Proceedings of the 2nd International Conference on Learning Analytics and Knowledge. LAK'12 (p. 134). doi:10.1145/2330601.2330636

Clow, D. (2013). An overview of learning analytics. Teaching in Higher Education, 18(6) 683-695. doi:10.1080/13562517.2013.827653

Dahlstrom, E., Walker, J. D, \& Dziuban, Ch. (2013). ECAR Study of Undergraduate Students and Information Technology (Research Report). Louisville, CO: EDUCAUSE Center for Analysis and Research. Retrieved from http://www. educause.edu/ecar

De Laat, M., \& Prinsen, F. (2014). Social Learning Analytics: Navigating the Changing Settings of Higher Education. Research and practice in assessment, 9(4), 51-60.

Douglas, K. A., Bermel, P., Monzurul Alam, M. D., \& Madhavan, K. (2016). Big data characterization of learner behaviour in a high technical MOOC engineering Course. Journal of Learning Analytics, 3(3), 170-192. doi:10.18608/ jla.2016.33.9

Drachsler, H. (2011). Turning Learning into Numbers - A Learning Analytics Framework. Open University of the Netherlands. Retrieved from http://www. slideshare.net/Drachsler/turning-learning-into-numbers-a-learning-analytics-framework

Ferguson, R., \& Buckingham, S. (2012). Social Learning Analytics: Five Approaches. In 2nd International Conference on Learning Analytics \& Knowledge (pp. 23-33). Vancouver, British Columbia, Canada. doi:10.1145/2330601.2330616

Hernández, Á., González, I., Jiménez, A. I., \& Chaparro, J. (2016). Visualizations of Online Course Interactions for Social Network Learning Analytics. International Journal of Emerging Technologies in Learning (iJET), 11(07), 6-15. doi:10.3991/ijet.v11i07.5889

Henríquez, M. A. (2003). Formación del profesorado en las Tecnologías de la Información y de la comunicación (Unpublished doctoral dissertation). Universidad Rovira i Virgili, Tarragona.

Henríquez, P. (2001). La aplicación didáctica de las TIC en la formación del siglo XXI (Unpublished doctoral dissertation). Universidad Rovira i Virgili, Tarragona.

Hernández, R., Fernández, C., \& Baptista, L. (2010). Metodología de la investigación. México: McGrawHill.

Johnson, L., Adams Becker, S., Cummins, M., Estrada, V., Freeman, A., \& Ludgate, H. (2013). NMC Horizon Report: 2013 Higher Education Edition. Austin, Texas: The New Media Consortium. Retrieved from http://www.nmc.org/ pdf/2013-horizonreport-HE.pdf

Leon, A., Corona, A., Yedra, R., Cruces, E., \& Gómez, J. (2015). Social Learning Analytics en grupos de Facebook, para la identificación de estudiantes de bajo desempeño. In IV Congresso Brasileiro de Informática na Educação (CBIE 2015). Maceió (Brasil).

Monroy, C., Snodgrass, V., \& Whitaker, R. (2014). A strategy for incorporating Learning Analytics into the Desing and Evaluation of a K-12 Science Curriculum. Journal of Learning Analytics, 1(2), 94-125. doi:10.18608/jla.2014.12.6

Nunn, S., Avella, J. T., Kanai, T., \& Kebritchi, M. (2016). Learning analytics methods, benefits, and challenges in higher education: A systematic literature review. Online Learning, 20(2). doi:10.24059/olj.v20i2.790

Oblinger, D. G. (2012). Let's talk analytics. EDUCAUSE Review, 47(4). Retrieved from http://net.educause.edu/ir/library/pdf/ERM1240P.pdf

Sclater, N., Peasgood, A., \& Mullan, J. (2016). Learning Analytics in Higher Education. A review of UK and international practice. Bristol: Jisc. Retrieved from https://www.jisc.ac.uk/sites/default/files/learning-analytics-in-he-v2_0.pdf

Siemens, G., \& Long, P. (2011). Penetrating the fog: Analytics in learning and education. EDUCAUSE review, 46(5), 30.

How to cite this article: Díaz, J. J., Solano, I. M., \& Sánchez, M. M. (2017). Social Learning Analytics in Higher Education. An experience at the Primary Education stage. Journal of New Approaches in Educational Research, 6(2), 119-126. doi: 10.7821/naer.2017.7.232 